\title{
Arrhythmias and ECG changes in life threatening hyperkalemia in older patients treated by potassium sparing drugs
}

\author{
Marie Berkova ${ }^{a}$, Zdenek Berka ${ }^{b}$ Eva Topinkova ${ }^{a}$
}

\begin{abstract}
Background. Severe hyperkalemia is a life threatening condition that can cause fatal rhythm disturbance and terminal heart arrest. The most common cause of hyperkalemia in older patients is that of iatrogenic medication-related etiology due to associated polymorbidity, polypharmacy and reduced reserve metabolic capacity. The aim of this paper is to increase awareness in the clinicians of the risk of hyperkalemia in elderly patients treated by potassium sparing drugs. Methods and Results. We present two case reports of hyperkalemia $\geq 9.0 \mathrm{mmol} / \mathrm{L}$ induced by potassium sparing medications with cardiac arrhythmias and severe ECG changes including atrial asystole, disturbance of intraventricular conduction and morphological changes such as tenting T waves and deformed wide QRS complexes. The most frequent causes of hyperkalemia in elderly patients are discussed and electrocardiogram changes and arrhythmias in hyperkalemia are analyzed, as well as their treatment and prevention.

Conclusion. Potassium sparing drug therapy in older persons requires more frequent monitoring especially when drugs or their doses are changed, or during concomitant acute illness.
\end{abstract}

Key words: hyperkalemia, electrocardiogram, potassium sparing drugs, elderly patients

Received: February 2, 2012; Accepted with revision: August 23, 2012; Available online: October 31, 2012 http://dx.doi.org/10.5507/bp.2012.087

${ }^{a}$ Department of Geriatrics, $1{ }^{\text {st }}$ Faculty of Medicine, Charles University, Prague, Czech Republic ${ }^{b}$ Department of Internal Medicine II - Gastroenterology and Hepatology, University Hospital Olomouc Corresponding author: Marie Berkova, e-mail: marie.berkova@lf1.cuni.cz

\section{INTRODUCTION}

Potassium imbalance represents the most common electrolyte disturbance in older patients. Though hypokalemia is known to be associated with increased hospitalization and mortality in patients with cardiovascular and renal diseases ${ }^{1,2}$, severe hyperkalemia is a life threatening condition too $^{3}$. It may be registered particularly in oligoanuric renal failure patients and other acute conditions (Table 1). However, more frequent use of angiotensin-converting enzyme inhibitors (ACEI), angiotensin II receptor antagonists and direct renin inhibitors, often combined with other potassium sparing drugs in the management of chronic cardiovascular diseases, contributed to increased incidence of clinically significant hyperkalemia in clinical practice, often in older patients $s^{4-12} .75 \%$ of hyperkalemia cases in institutionalized patients are induced by potassium sparing drugs (Table 2). Hyperkalemia $\geq 6 \mathrm{mmol} / \mathrm{L}$ is observed in $0.8 \%$ of ACEI and $2.8 \%$ of angiotensin II receptor antagonist users ${ }^{13}$. The combination of potassium sparing drugs multiplies the risk of this adverse drug event. The mortality rates of patients with hyperkalemia over $7.0 \mathrm{mmol} / \mathrm{L}$ reach $67 \%$ if not promptly corrected ${ }^{14,15}$. Due to changes in pharmacokinetics and pharmacodynamics adverse drug reactions (ADR) are more common in older people. Age-related changes in drug absorption, body composition and drug distribution compartments, reduction of metabolic and elimination reserve capacities (renal and hepatic functions), chronic polymorbidity accompanied by polypharmacy are among factors contributing to increased risk of ADR (ref. $\left.{ }^{16}\right)$. In this article we present two recent case reports of severe hyperkalemia in older patients.

\section{CASE REPORT 1}

An 83-year-old Caucasian woman was referred to the Emergency Department of Internal Medicine for progressive worsening of generalized muscle weakness and bradycardia 40 beats/min. Administration of Atropin $0.5 \mathrm{mg}$

Table 1. The causes of hyperkalemia.

- Renal failure with reduced diuresis

- Severe acidosis (e.g. diabetic ketoacidosis), Hyperglycemia

- Drugs

- Dehydration

- Rhabdomyolysis, polytrauma, crush syndrome, severe burns

- Catabolic conditions

- Addison's disease

- Hypoaldosteronism

- Repeated blood transfusion

- Tumor lysis syndrome (after cytostatic therapy)

- Rare tubular syndromes (Gordon syndrome)

- Hemolysed blood sample (repeat sample)

- High platelet or white blood count (artificially raise potassium level)-repeat sample in Lithium heparin 
i.v. was ineffective. The patient with the history of arterial hypertension, moderate mitral valve insufficiency, type 2 diabetes mellitus controlled by diet therapy, mild diabetic and hypertensive nephropathy with proteinuria (with creatinine in the normal range) was hospitalized four years ago for paroxysmal atrial fibrillation with rapid ventricle response and acute heart failure. Since that time she was treated with digoxin $0.25 \mathrm{mg}$ tbl. 1-0-0, diltiazem $60 \mathrm{mg}$ tbl. 1-0-0, losartan $50 \mathrm{mg}$ tbl. 1-0-0, spironolactone $25 \mathrm{mg}$ tbl. 1-0-1, amiloride/hydrochlorothiazide 5/50 mg tbl. $1 / 2-0-0$ and warfarin $3 \mathrm{mg}$ tbl. $1-0-0$. She did well until the last few days when fatigue and progressive muscle weakness appeared. She was unable to stand up, much less to walk, although she was self-sufficient till that time. In the last two days, diarrhoea appeared. Urination was normal and the urine was of normal colour and quantity. No other subjective problems were reported by the patient. On physical examination: weight $75 \mathrm{~kg}$, height $170 \mathrm{~cm}$, BMI $26 \mathrm{~kg} / \mathrm{m}^{2}$, supine blood pressure 160/90 $\mathrm{mmHg}$, pulse 40 beats/minute. The patient was fully oriented but bradypsychic, unable either to stand up or to sit due to profound muscle weakness, without significant signs of skin dehydration but with gently stale mucous membranes and tongue. Neurological reflexes were preserved but of slow motion response and quiet systolic murmur $(2 / 6)$ was heard above mitral valve. Otherwise physical findings were normal.

Electrocardiogram at admission showed no atrial electric activity, regular rescue ventricular rhythm with 180 ms wide abnormal QRS complexes, rate 40/min. Higher $\mathrm{T}$ wave were seen especially in limb leads II, III, aVF (Fig. 1). Laboratory examination at admission showed extreme potassium level $9.62 \mathrm{mmol} / \mathrm{L}$ that was confirmed by repeated examination (Table 3 ). The patient was admitted to the Intensive Care Unit (ICU), a central venous
Table 2. The most common drugs that may increase serum potassium level.

- Potassium substituents

- Potassium sparing diuretics (e.g. amiloride)

- Aldosterone antagonists - spironolactone, eplerenone

- Angiotensin-converting enzyme inhibitors (ACEI), angiotensin II antagonists, direct renin inhibitors

- Nonsteroidal anti-inflammatory drugs

- Heparin, low molecular weight heparins

- Cyclosporin A

- Crystallic Penicillin (potassium salt)

catether inserted and after initial administration of 10 $\mathrm{ml}$ of calcium gluconicum $10 \%$ twice repeatedly, glucose/ insulin and rehydration infusions were applied. For mild metabolic acidosis solution of sodium bicarbonate $4.2 \%$ $200 \mathrm{~mL}$ was administered. After sufficient hydration had been achieved, infusions with potassium wasting diuretics (furosemide) were administered. The treatment was fortified with peroral resin Calcium polystyrene sulfonate (Calcium resonium) $15 \mathrm{~g}$ orally four times per day. Consequently serum potassium level gradually decreased till the normal range was achieved (Fig. 2). With serum electrolyte improvement the ventricular rhythm was replaced at first with sinus bradycardia with borderline prolongation of PQ interval of $200 \mathrm{~ms}$ and narrow QRS complex $110 \mathrm{~ms}$, followed by sinus rhythm with heart rate 70 beats/min converting occasionally to atrial fibrillation (Fig. 3). With normalization of serum potassium level the muscle weakness and diarrhoea subsided. On the sixth day the patient was discharged in clinically stable condition and independent. The drug regimen was modified

Table 3. Biochemical results of the woman - patient, Case 1.

\begin{tabular}{|c|c|c|c|}
\hline Biochemical examination & At admission & At discharge & Normal range \\
\hline Natrium & $132 \mathrm{mmol} / \mathrm{L}$ & $137.0 \mathrm{mmol} / \mathrm{L}$ & $130-144 \mathrm{mmol} / \mathrm{L}$ \\
\hline Potassium & $9.6 \mathrm{mmol} / \mathrm{L}$ & $4.31 \mathrm{mmol} / \mathrm{L}$ & $3.6-5.4 \mathrm{mmol} / \mathrm{L}$ \\
\hline Chloride & $114 \mathrm{mmol} / \mathrm{L}$ & $110.0 \mathrm{mmol} / \mathrm{L}$ & $95-110 \mathrm{mmol} / \mathrm{L}$ \\
\hline Magnesium & $1.01 \mathrm{mmol} / \mathrm{L}$ & $0.86 \mathrm{mmol} / \mathrm{L}$ & $0.80-1.05 \mathrm{mmol} / \mathrm{L}$ \\
\hline Osmolality & $305 \mathrm{mmol} / \mathrm{kg}$ & & $275-300 \mathrm{mmol} / \mathrm{kg}$ \\
\hline Urea & $14.5 \mathrm{mmol} / \mathrm{L}$ & $9.2 \mathrm{mmol} / \mathrm{L}$ & $2.8-8.3 \mathrm{mmol} / \mathrm{L}$ \\
\hline Creatinine & $193.0 \mu \mathrm{mol} / \mathrm{L}$ & $128 \mu \mathrm{mol} / \mathrm{L}$ & $53.0-124.0 \mu \mathrm{mol} / \mathrm{L}$ \\
\hline Glucose & $8.4 \mathrm{mmol} / \mathrm{L}$ & $4.7 \mathrm{mmol} / \mathrm{L}$ & $3.9-5.6 \mathrm{mmol} / \mathrm{L}$ \\
\hline Glomerular filtration (GFMD): & $0.4 \mathrm{ml} / \mathrm{sec} / 1.73 \mathrm{~m} 2$ & & $1.5 \pm 0.5 \mathrm{ml} / \mathrm{s} / 1.73 \mathrm{~m}^{2}$ \\
\hline Lactate & $2.35 \mathrm{mmol} / \mathrm{L}$ & & $0.00-2.40 \mathrm{mmol} / \mathrm{L}$ \\
\hline Digoxin & $1.75 \mathrm{nmol} / \mathrm{L}$ & & $0.90-2.10 \mathrm{nmol} / \mathrm{L}$ \\
\hline pH capillar & 7.23 & & 7.34-7.44 \\
\hline $\mathrm{HCO}_{3}$ standard & $15.9 \mathrm{mmol} / \mathrm{L}$ & & $21-26 \mathrm{mmol} / \mathrm{L}$ \\
\hline $\mathrm{HCO}_{3}$ actual & $17 \mathrm{mmol} / \mathrm{L}$ & & $21-26 \mathrm{mmol} / \mathrm{L}$ \\
\hline Base excess $(\mathrm{BE})$ & $-9.4 \mathrm{mmol} / \mathrm{L}$ & & -2.0 to $+2.0 \mathrm{mmol} / \mathrm{L}$ \\
\hline
\end{tabular}



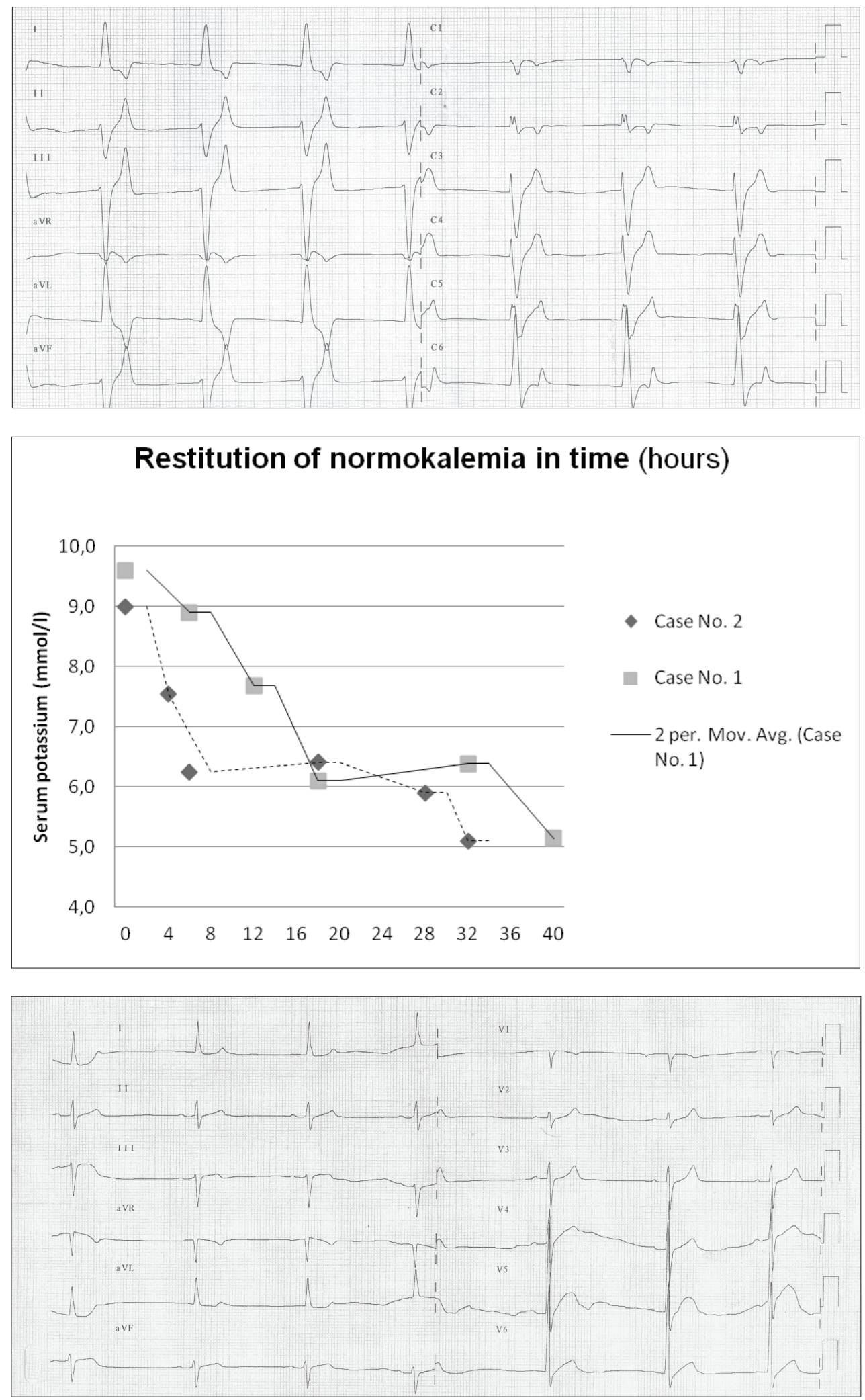

Fig. 1. ECG of the woman at admission - hyperkalemia $9.62 \mathrm{mmol} / \mathrm{L}$ (case 1).

Fig. 2. The graph of blood potassium level in time.

Fig. 3. ECG early after restoration of normokalemia (case 1).

with reduction of diuretics including potassium sparing amiloride. On follow-ups her serum potassium was repeatedly within normal range. Bradycardia did not re-occur.

\section{CASE REPORT 2}

The 73-old male with type 2 diabetes on insulin therapy with the history of hypertension, myocardial infarc- tion, coronary artery bypass grafting (CABG) some years ago and chronic first degree atrioventricular block was referred to a hospital admission for growing weakness particularly of lower extremities with inability to stand. The patient's medication included chronic intensive insulinotherapy (rapid acting insulin human recombinant HMR 24-6-18-6-18-6-8 IU s. c. a day), acetylsalicylic acid $100 \mathrm{mg}$ tbl. $0-1-0$, ramipril $10 \mathrm{mg}$ tbl. $1-0-0$, spironolactone $100 \mathrm{mg}$ tbl. 1-0-0, hydrochlorothiazide/amiloride 25/2.5 
Table 4. Biochemical results of the man - patient, Case 2.

\begin{tabular}{lccc}
\hline Biochemical examination & At admission & At discharge & Normal range \\
\hline Natrium & $130 \mathrm{mmol} / \mathrm{L}$ & $143.0 \mathrm{mmol} / \mathrm{L}$ & $130-144 \mathrm{mmol} / \mathrm{L}$ \\
Potassium & $9.0 \mathrm{mmol} / \mathrm{L}$ & $4.84 \mathrm{mmol} / \mathrm{L}$ & $3.6-5.4 \mathrm{mmol} / \mathrm{L}$ \\
Chloride & $105 \mathrm{mmol} / \mathrm{L}$ & $113.0 \mathrm{mmol} / \mathrm{L}$ & $95-110 \mathrm{mmol} / \mathrm{L}$ \\
Magnesium & $0.71 \mathrm{mmol} / \mathrm{L}$ & $0.85 \mathrm{mmol} / \mathrm{L}$ & $0.80-1.05 \mathrm{mmol} / \mathrm{L}$ \\
Osmolality & $321 \mathrm{mmol} / \mathrm{kg}$ & $290 \mathrm{mmol} / \mathrm{kg}$ & $275-300 \mathrm{mmol} / \mathrm{kg}$ \\
Urea & $15.1 \mathrm{mmol} / \mathrm{L}$ & $8.3 \mathrm{mmol} / \mathrm{L}$ & $2.8-8.3 \mathrm{mmol} / \mathrm{L}$ \\
Creatinine & $207.0 \mu \mathrm{mol} / \mathrm{L}$ & $102 \mu \mathrm{mol} / \mathrm{L}$ & $53.0-124.0 \mu \mathrm{mol} / \mathrm{L}$ \\
Glucose & $28.8 \mathrm{mmol} / \mathrm{L}$ & $9.2 \mathrm{mmol} / \mathrm{L}$ & $3.9-5.6 \mathrm{mmol} / \mathrm{L}$ \\
HbAlc & $11.1 \%$ & & $2.8-4.0 \%$ \\
Glomerular filtration (GFMD): & $0.46 \mathrm{~mL} / \mathrm{sec} / 1.73 \mathrm{~m}^{2}$ & 1.04 & $1.5 \pm 0.5 \mathrm{~mL} / \mathrm{s} / 1.73 \mathrm{~m}^{2}$ \\
Lactate $_{\text {pH venous }}$ & $2.8 \mathrm{mmol} / \mathrm{L}$ & & $0.00-2.40 \mathrm{mmol} / \mathrm{L}$ \\
$\mathrm{HCO}_{3}$ standard & 7.19 & 7.35 & $7.34-7.44$ \\
$\mathrm{HCO}_{3}$ actual & $19.5 \mathrm{mmol} / \mathrm{L}$ & & $21-26 \mathrm{mmol} / \mathrm{L}$ \\
Base excess & $17 \mathrm{mmol} / \mathrm{L}$ & $21-26 \mathrm{mmol} / \mathrm{L}$
\end{tabular}
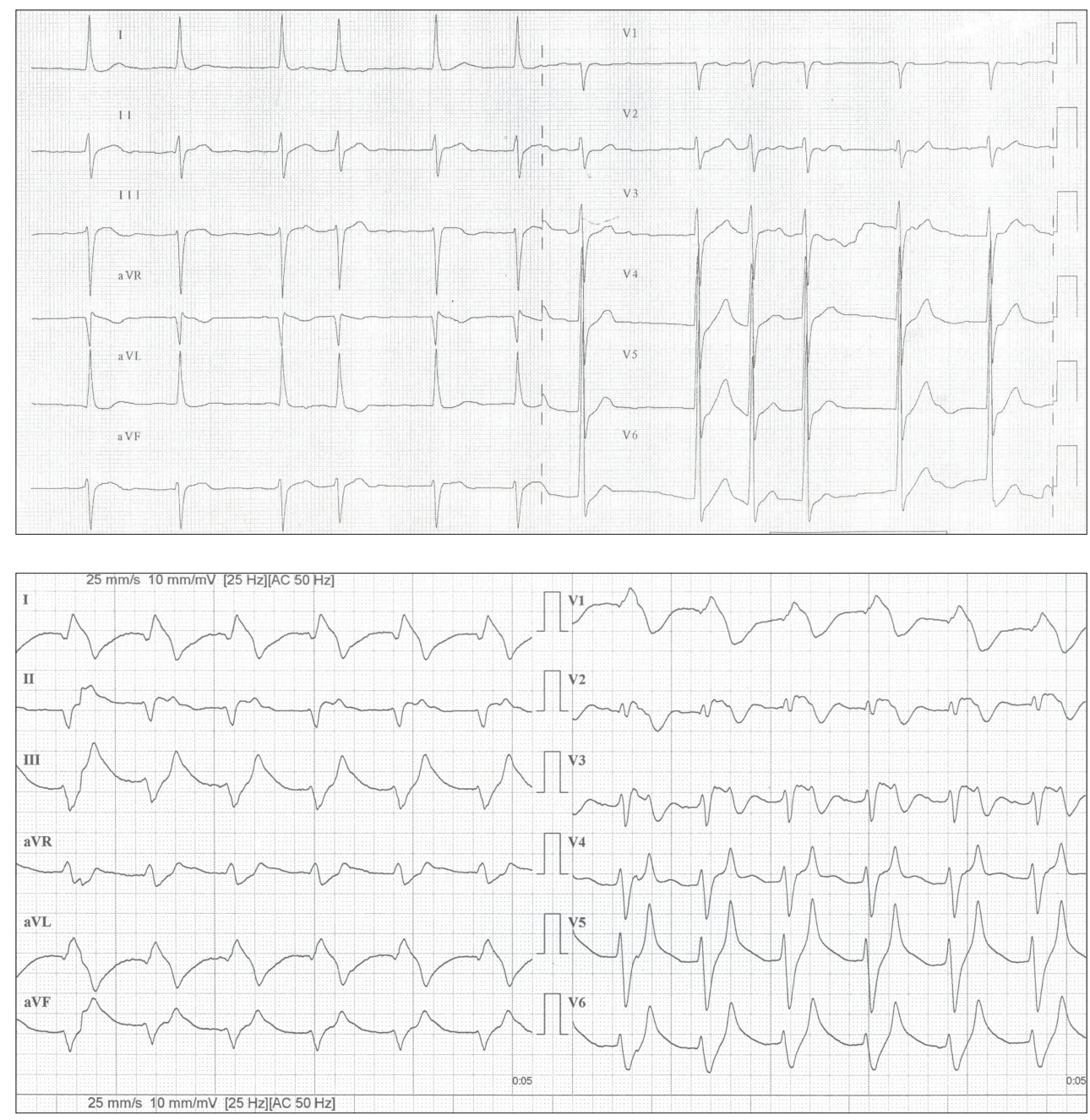

Fig. 4. ECG more than $24 \mathrm{~h}$ after restoration of normokalemia (case 1).

Fig. 5. ECG of the man at admmission - hyperkalemia $9.0 \mathrm{mmol} / \mathrm{L}$ (case 2). 


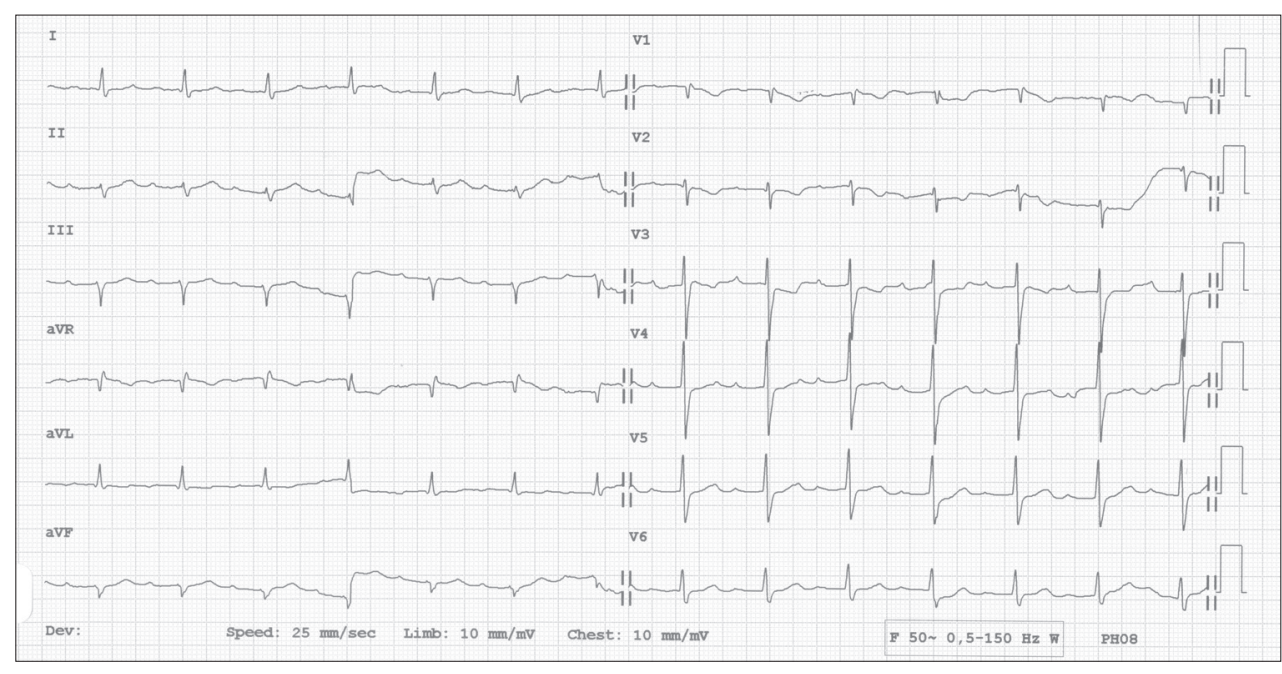

Fig. 6. ECG after the restoration of normokalemia in the man (case 2). mg tbl. 1-0-0 and rosuvastatin $20 \mathrm{mg}$ tbl. 0-0-1. On admission the patient (height $179 \mathrm{~cm}$, weight $90 \mathrm{~kg}$, BMI 28.0 $\mathrm{kg} / \mathrm{m}^{2}$ ) was fully oriented but unable to stand or sit, supine blood pressure $150 / 90 \mathrm{mmHg}$, heart frequency of $73 / \mathrm{min}$.

On the electrocardiogram the $\mathrm{P}$ waves were not differentiated and bizzare wide QRS complexes 73/per minute were present (Fig. 5). The biochemistry revealed hyperglycemia $(27.5 \mathrm{mmol} / \mathrm{L})$, acidosis $(\mathrm{pH} 7.21$, base excess $-9.0 \mathrm{mmol} / \mathrm{L}$ ) and mineral imbalance with hyperkalemia $9.0 \mathrm{mmol} / \mathrm{L}$ (Table 4). After urgent treatment at the Emergency Department $(0.9 \%$ solution of sodium chloride $500 \mathrm{ml}$, Humulin R $20 \mathrm{IU}$, sodium bicarbonate $4.2 \%$ solution $200 \mathrm{ml}$, Calcium gluconicum $10 \% 20 \mathrm{ml}$ and Furosemide $20 \mathrm{mg}$ intravenously, Calcium resonium 30 g p.o.) in hemodynamically stable patient the short hemodialysis was carried out. The decompensated diabetes mellitus was controlled by adjusted dosage of rapid acting insulin. After the restoration of homeostasis (Fig. 2) the warning ECG changes disappeared and sinus rhythm with chronic first degree atrioventricular block and narrow QRS complexes was restored (Fig. 6).

\section{DISCUSSION AND ANALYSIS OF HYPERKALEMIA ETIOLOGY}

\section{Potassium metabolism}

Potassium is a vital ion and most potassium is intracellular (98\%). The mechanism controlling the intra and extra celullar difference is the sodium-potassium pump $(\mathrm{Na}+/ \mathrm{K}+$-ATPase $)\left(\right.$ ref. $\left.{ }^{17}\right)$. The serum potassium concentration is consistently associated with changes in $\mathrm{pH}$ (ref. ${ }^{18}$ ). The normal kidney function is important for maintenance of potassium balance. Potassium is mainly excreted in distal tubules (some potassium is also lost via the digestive tract and sweat).

An important role in the metabolism of potassium is played by the renin - angiotensin - aldosterone system. Aldosterone acts on mineralocorticoid receptors of the cells of the distal tubule and the collecting duct of the kidney nephron and activates the $\mathrm{Na}^{+} / \mathrm{K}^{+}$pump. The result of this process is reabsorption of sodium and excretion of potassium ions. ACEI, angiotensin II receptor antagonists and direct renin inhibitors decrease secretion of aldosterone and can cause potassium retention ${ }^{19-22}$.

The inhibition of vasodilating prostaglandine production by cyclooxygenase inhibitors especially in patients with chronic heart failure can significantly reduce renal perfusion, glomerular filtration and tubular potassium excretion followed by hyperkalemia ${ }^{17}$.

\section{Hyperkalemia and muscle and myocardial function}

Hyperkalemia slows down neuromuscular conduction and particularly in combination with negative chronotropic drugs can cause heart arrest. While mild hyperkalemia (5.5-6.0 mmol/L) causes no ECG changes, in moderate hyperkalemia $(6.1-7.0 \mathrm{mmol} / \mathrm{L})$ the ECG changes may be discreet and non specific ${ }^{23}$. The initial typical ECG changes in hyperkalemia are usually narrow and spiked $\mathrm{T}$ waves, shortening of QT interval and merging $\mathrm{T}$ reflecting acceleration of the terminal phase of ventricular repolarization. In severe hyperkalemia (serum potassium $>7.0 \mathrm{mmol} / \mathrm{L}$ ), sinus bradycardia, widening and flattening of $\mathrm{P}$ waves, conduction disturbances with prolongation of PR interval, wider QRS complex, Tawar bundle branch blocks, atrioventricular blockades (blockade of sodium channels) and ectopic electric activity can by seen. Sporadically ST depression with T wave inversions or ST elevation which may mimic acute myocardial infarction have been described ${ }^{24-33}$. The most severe hyperkalemia is represented by disappearance of $P$ waves and sinus rhythm is replaced by emergency junction or ventricular rhythm with bizarre shape QRS. The terminal rhythm is ventricular fibrillation and heart arrest ${ }^{34}$. A potassium level of about $10.0 \mathrm{mmol} / \mathrm{L}$, but often much lower, is definitely incompatible with life.

Hyperkalemia - induced failure of not only atrial capture with preserved ventricular pacing in a patient with a dual-chamber (DDD) pacemaker ${ }^{35}$ but also failure of both the atrial and the ventricular pacemaker captures have been reported ${ }^{36}$. The ECG changes are strong impetus for urgent treatment of hyperkalemia. The 12-lead ECG and vital function monitoring in severe hyperkalemia is mandatory.

In two case reports, we described excessive hyperkalemia with severe cardiac conduction disturbances. In the 
first case potassium sparing drugs and mild dehydration were the causal factors of hyperkalemia. In the second case it was decompensated insulin dependent type 2 diabetes mellitus further potentiated the effect of potassium sparing diuretics. Bradycardia in the first case might have been associated with negatively chronotropic effects of concomitant use of diltiazem and digoxin, though the serum digoxin level was within the normal therapeutic range. But it is known, that old people are more sensitive to digoxine due to smaller distribution volume, possible drug interactions, limited renal function and higher sensitivity of $\mathrm{Na}^{+} / \mathrm{K}^{+}$-ATPase for digoxin. For this reason, a lower therapeutic level of digoxin $0.6-1.2 \mathrm{nmol} / \mathrm{L}$ is recommended in older patients compared to young and middle aged groups.

The presented patients were of advanced age, which put them at a higher risk of electrolyte disturbances. The main risk factors for hyperkalemia in the elderly are: limited metabolic and excretion function reserves ${ }^{37}$, changes in body composition and drug distribution compartments, decline of sensory and cognitive functions with limited ability to promptly and adequately respond to external changes, polymorbidity and polypharmacy ${ }^{19,37}$, that involve drugs influencing potassium homeostasis (potassium sparing diuretics, ACEI, angiotensin II receptor antagonists, direct renin inhibitors, non steroid antiinflammatory drugs, corticosteroids, beta blockers, some antibiotics, long term treatment by heparin). In the Czech Republic, polypharmacy may play a significant role as the average number of drugs prescribed to Czech seniors is high: 4-6 drugs in community-living elderly and 5-8 drugs in institutional care ${ }^{16}$. In both presented case reports, the cause of hyperkalemia was multifactorial.

Clinical symptoms of hyperkalemia differ in relation to serum potassium level. Mild hyperkalemia is mostly well tolerated, moderate hyperkalemia may be asymptomatic as well. However, with increasing hyperkalemia the symptoms appear. The most frequent are weakness, fatigue, diarrhoea and confusion ${ }^{34}$. In hyperkalemia $>6.5$ $\mathrm{mmol} / \mathrm{L}$ hospital admission is warranted with monitoring of cardiac rhythm and urgent therapy.

In the referred older patients, severe changes in ECG were present that - if not treated - could have led to death. The rescue chamber rhythm is the ultimate rhythm often followed by heart arrest. Despite a heartbeat of 40/ min, the patient case 1 tolerated bradycardia very well without signs of heart failure and without the necessity for installing temporary pacemaker ${ }^{38}$. Although in hyperkalemia the peaked T waves mostly in all leads are usually described, in the first case we saw the highest tenting $\mathrm{T}$ waves only in the limb leads II, III, aVF, whereas in the second case the highest $\mathrm{T}$ waves were recorded in the limb lead II and the chest leads V4-6. The microbiological examination did not reveal an infectious etiology of the diarrhoea in case 1 and it was found to be one of the signs of hyperkalemia. With restoration of homeostasis, the diarrhoea vanished too. Hyperkalemia can be accompanied by other gastrointestinal symptoms such as stomach ache and vomiting, that were not present in reported patients.
However, both patients reported a typical symptom - severe muscle weakness.

\section{Treatment of hyperkalemia}

The treatment of the woman in the first case report started with glucose infusion with rapid acting insulin. The infusion application was necessary to achieve sufficient hydration and to permit administration of potassium wasting diuretics (furosemide). The usual dosage of furosemide is $40-120 \mathrm{mg}$ intravenously, in patients with renal failure and substantional fluid retention the dose may be increased. The rapid acting insulin in $10 \%$ glucose solution (more concentrated glucose may be administered into the central vein system) does not eliminate potassium from the body but shifts it from the extracelullar compartment into the cells ${ }^{39}$. In the second case the therapy was initiated by rapid acting insulin without glucose but $0.9 \%$ sodium chloride solution as the patient suffered from decompensated diabetes mellitus with hyperglycemia (Table 6). American Heart Association Guidelines for Cardiopulmonary Resuscitation and Emergency Cardiovascular Care guidelines for the management of hyperkalemia in adults 2005 recommend in the case of hyperkalemia $>7 \mathrm{mEq} / \mathrm{L}$ with toxic ECG changes the use of $5-10 \mathrm{~mL}$ of Calcium chloride 10\% (Calcium gluconicum $10 \%$ contains $1 / 3$ the elemental calcium of Calcium chloride) intravenously over 3-5 min to shift potassium into the cells and reduce the effects of potassium at the myocardial cell membrane (it lowers the risk of ventricular fibrillation) (ref. ${ }^{40}$ ). The patients were closely monitored and we also administrated $10 \%$ Calcium gluconicum 10 $\mathrm{ml}$ though the effect of this treatment is transient (approximately $30 \mathrm{~min}$ ) and the patients ' cardiopulmonary conditions despite ECG changes and bradycardia were stable. However, in digoxin treated patients, treatment with i.v. calcium may increase the toxicity of digoxin.

Some studies have reported that beta adrenergic agonists can shift the potassium into the cells. Inhalation of $10 \mathrm{mg}$ of nebulized salbutamol was reported to induce a short term(about one minute) increase of hyperkalemia $0.15 \mathrm{mEq} / \mathrm{L}$ followed in $3-5 \mathrm{~min}$ by a decline ranging from 0.4 to $1.5 \mathrm{mEq} / \mathrm{l}$ and lasting up to $2-4 \mathrm{~h}$, after which the level steadily increases to the original plasma potassium value $^{41-43}$. However, up to one third of patients with hyperkalemia do not respond to this therapy. Apart from the transient effect of salbutamol, the dosage for the treatment of hyperkalemia is many times higher (4-8x) than that one for bronchial obstruction therapy. It may cause severe adverse effects (flush, tremor, anxiety, tachycardia, arrhythmias) and be hazardous particularly in patients with cardiovascular diseases and in the elderly. There have been no convincing clinical trials using beta adrenergic agonists in the management of severe hyperkalemia and some experts consider this treatment not to be evidence based $^{44,45}$, although some guidelines admit this therapy ${ }^{46}$. We do not use beta adrenergic agonists for the treatment of hyperkalemia either.

Calcium polystyrene sulfonate was added to the therapy of our patients to remove potassium from the body. The resin exchanges calcium for potassium ions ${ }^{47}$. 
The treatment of severe bradycardia with heart failure may be the temporary pacing under the condition that the myocardium is capable to respond to the stimuli ${ }^{48}$. Despite severe hyperkalemia there was no need for pacing in our patients.

In patient 2 in addition to pharmacological treatment, hemodialysis was performed that could be like hemofiltration definite treatment if other options fail ${ }^{49}$. Using hemodialysis was very effective with steeper decline in serum potassium levels. In patient 1 , hemodialysis was not commenced as the patient was hemodynamically stable and rehydration enabled loop diuretics use (furosemide). However, in this patient serum potassium decrease was slower than in the patient treated with hemodialysis.

\section{CONCLUSION}

Severe hyperkalemia is a life threatening condition and is considered to be a common cause of sudden death. The incidence of hyperkalemia is increasing in the elderly given the large number of risk factors. Potassium sparing drugs play an important role in the development of hyperkalemia. ECG changes are warning signs in hyperkalemia that must be treated without delay. Prevention of hyperkalemia and its complications encompasses more frequent monitoring of serum potassium levels particularly in patients treated with potassium influencing drugs or when drug dosis is changed and in case of acute illness. Adequate hydration is important. The development of new drugs to treat and prevent hyperkalemia, e.g. new polymeric potassium binders may improve health outcomes for patients at risk ${ }^{50}$.

\section{CONFLICT OF INTEREST STATEMENT}

The authors stated that there are no conflicts of interest regarding the publication of this article.

\section{REFERENCES}

1. Bowling CB, Pitt B, Ahmed MI, Aban IB, Sanders PW, Mujib M, Campbell RC, Love TE, Aronow WS, Allman RM, Bakris GL, Ahmed A. Hypokalemia and outcomes in patients with chronic heart failure and chronic kidney disease: findings from propensity-matched studies. Circ Heart Fail 2010;3:253-60.

2. Weir MR, Rolfe M. Potassium homeostasis and renin-angiotensinaldosterone system inhibitors. Clin J Am Soc Nephrol 2010;5:531-8

3. Bozkurt B, Agoston I, Knowlton AA. Complications of inappropriate use of spironolactone in heart failure: when an old medicine spirals out of new guidelines. J Am Coll Cardiol 2003;41:211-4.

4. Yüksel S, Çölbay M, AcartürkG, Uslan I, Karaman O, Maralcan M, Yavuz Y. Severe Hyperkalemia: A Retrospective Analysis. European Journal of General Medicine 2008;5(2):80-3.

5. Sica DA. Hyperkalemia risk in chronic kidney disease. deterrent to the use of aldosterone receptor antagonism or not. Hypertension 2009;53:754-60.

6. Palmer BF. Hypertension management in patients with chronic kidney disease. Curr Hypertens Rep 2008;10(5):367-73.

7. Schrier RW, Masoumi A, Elhassan E. Aldosterone: role in edematous disorders, hypertension, chronic renal failure, and metabolic syndrome. Clin J Am Soc Nephrol 2010;5:1132-40.
8. Slagman MC, Navis G, Laverman GD. Dual blockade of the reninangiotensin-aldosterone system in cardiac and renal disease. Curr Opin Nephrol Hypertens 2010;19:140-52.

9. Cavallari LH, Groo VL, Viana MA, Dai Y, Patel SR, Stamos TD. Association of aldosterone concentration and mineralocorticoid receptor genotype with potassium response to spironolactone in patients with heart failure. Pharmacotherapy 2010;30:1-9.

10. Einhorn LM, Zhan M, Hsu VD, Walker LD, Moen MF, Seliger SL, Weir MR, Fink JC. The frequency of hyperkalemia and its significance in chronic kidney disease. Arch Intern Med 2009;169:1156-62.

11. Juurlink DN, Mamdani MM, Lee DS, Kopp A, Austin PC, Laupacis A, Redelmeier DA. Rates of hyperkalemia after publication of the Randomized Aldactone Evaluation Study. N Engl J Med 2004;351:543-51.

12. Wei L, Struthers AD, Fahey T, Watson AD, Macdonald TM. Spironolactone use and renal toxicity: population based longitudinal analysis. BMJ 2010;340:c1768.

13. Sadjadi SA, McMillan Jl, Jaipaul N, Blakely P. A comparative study of the prevalence of hyperkalemia with the use of angiotenstinconverting enzyme inhibitors versus angiotensin receptor blockers. Dovepress J 2009,5:547-52.

14. Mclntyre WF, Femenía F, Arce M, Pérez-Riera AR, Baranchuk A. Importance of early electrocardiographis recognition and timely management of hyperkalemia in geriatric patients. Exp Clin Cardiol 2011;16(2):47-50.

15. Weisberg LS. Management of severe hyperkalemia. Crit Care Med 2008;36:3246-51.

16. Kubešová H, Holík J, Šipr K, Bogrová I. Farmakoterapie starších klientů praktického lékaře - teorie a skutečnost. Geriatria 2000,6:2732.

17. Tesař V. Hypokalémie a hyperkalémie. Postgraduální medicína 2010;12(5):574-8.

18. Nyirenda MJ, Tang Jl, Padfield PL, Seckhl JR. Hyperkalaemia. Br Med J 2009; 339:1019-24.

19. Kokot F, Hyla-Klekot L. Drug-induced abnormalities of potassium metabolism. Polskie Archiwum Medycyny Wewnetrznej 2008;118, pp. 431-3.

20. Khanna $A$, White WB. The management of hyperkalemia in patients with cardiovascular disease. Am J Med 2009;122, pp. 215-21.

21. Venzin RM, Cohen CD, Maggiorini M, Wüthrich RP. Aliskirenassociated acute renal failure with hyperkalemia. Clin Nephrol 2009;98:326-8.

22. Oster JR, Singer I, Fishman LM. Heparin-induced aldosterone suppression and hyperkalemia. Am J Med 1995;71:575-86.

23. Parham WA, Mehdirad AA, Biermann KM, BS, Fredman CS. Hyperkalemia Revisited, Tex Heart Inst J 2006;33(1):40-7.

24. Walter RB, Bachli EB. Images in cardiology. Near fatal arrhythmia caused by hyperkalemia. Heart 2002;88(6):578.

25. Luzza F, Carey S, Oreto G. Images in cardiology. An unusual hyperkalemia induced block. Heart 2001;86:686 doi:10.1136/heart.86.6.686

26. Manohar N, Young ML. Rate dependent bundle branch block induced by hyperkalemia. Pacing Clin Electrophysiol 2003;26(9):190910.

27. Wang K, Asinger RW, Marriott HJ. ST segment elevation in conditions other than acute myocardial infarction. $N$ Engl J Med 2003;349(22):2128-35.

28. Vereckei A. Inferior wall pseudoinfarction pattern due to hyperkalemia. Pace 2003;26:2181-4.

29. Kim NH, Oh SK, Jeong JW. Hyperkalemia induced complete atrioventricular block with a narrow QRS complex. Heart 2005;91:e5 doi:10.1136/hrt.2004.046524

30. Goranitou G, Stavrianaki D, Babalis D. Wide QRS tachycardia caused by severe hyperkalemia and digoxin intoxication. Acta Cardiol 2005;60(4):437-41.

31. Tiberti G, Bana G, Bossi M. Complete atrioventricular block with widened QRS complex during hyperkalemia. Pacing Clin Electrophysiol 1998;21(7):1480-2.

32. Seto A, Murakami M, Fukuyama H, Kuniyuki N, Kazuyoshi A, Takenakana I, Kadoya T. Ventricular tachycardia caused by hyperkalemia after administration of hypertonic mannitol. Anesthesiology 2000;93(5):1359-61.

33. Sims DB, Sperling LS. ST-Segment Elevation Resulting From Hyperkalemia. Circulation. 2007;116:e2-e4.

34. McGuigan J, Robertson S, Isles C. Life threatening hyperkalemia 
with diarrhoea during ACE inhibition. Emerg Med J 2005;22:154-5. doi:10.1136/emj.2003.011734

35. Barold SS, Falkoff MD, Ong LS, Heinle RA. Hyperkalemia induced failure of atrial capture during dual-chamber cardiac pacing. J Am Coll Cardiol 1987;10(2):467-9.

36. Kahloon MU, Aslam AK, Aslam AF, Wilbur SL, Vasavada BC, Khan IA. Hyperkalemia induced failure of atrial and ventricular pacemaker capture. Int J Cardiol 2005;105(2):224-6.

37. Poggio R, Grancelli HO, Miriuka SG. Understanding the risk of hyperkalaemia in heart failure: role of aldosterone antagonism. Postgrad Med J 2010;86:136-42. doi:10.1136/pgmj.2008.072058

38. Pajerek J, Štolcová A, Fialka J. Otrava kaliem. Pediatria pre prax, 2006;1:42-4.

39. Carvalhana V, Burry L, Lapinsky SE. Management of severe hyperkalemia without hemodialysis: Case report and literature review. J Crit Care 2006;21(4):316-21.

40. ECC Committee: American Heart Association Guidelines for Cardiopulmonary Resuscitation and Emergency Cardiovascular Care, Circulation 2005;112(24 Suppl):IV1-203.

41. Sood MM, Sood AR, Richardson R. Emergency management and commonly encountered outpatient scenarios in patients with hyperkalemia. Mayo Clin Proc 2007;82(12):1553-61.

42. Chardos J.Timing of Administration of Beta-Agonists. Mayo Clin Proc 2008;83(3):368-73.

43. Mandelberg A, Krupnik Z, Houri S, Smetana S, Gilad E, Matas Z, Priel
IE. Salbutamol metered-dose inhaler with spacer for hyperkalemia: how fast? how safe? Chest 1999;115(3):617-22.

44. Dimmitt SB. Salbutamol unsafe in hyperkalaemia. Brit Med J 2009;339/b4114. doi:10.1136/bmj.b4114

45. Kamel SK, Wei C. Controversial issues in the treatment of hyperkalaemia. NDT 2003;18(111):2215-18.

46. Mc Veigh G, Maxwell P, O’Donnell S. Guidelines for the treatment of hyperkalaemia in adults. 2008, pp 13-4. Belfast Health and Social Care Trust 2008, GAIN, Stormont Belfast. ISBN 978-1-906805-02-9.

47. Sørensen MV, Matos JE, Praetorius HA, Leipziger J. Colonic potassium handling. Pflugers Arch 2010;459(5):645-56.

48. Chakraborty B, Rahman M, Ahmed QS, Rahman MM. Life threatening hyperkalemia requiring prolonged temporary pacing support: A case report and an analysis of electrocardiographic ganges. Orion Med J 2006;25:411-3.

49. Mckellar G, Alfonzo A, Isles C.Hyperkalemia: causes, electrocardiographic changes and management. J R Coll. Physicians Edinb 2006;36:5-11.

50. Pitt B, Anker SD, Bushinsky DA, Kitzman DW, Zannad F, Huang I-Z. Evaluation of the efficacy and safety of RLY5016, a polymeric potassium binder, in a double-blind, placebo-controlled study in patients with chronic heart failure (the PEARL-HF) trial. Eur Heart J 2011;32(7):820-8 